\title{
A Stochastic Model to Assess the Effect of Meat Inspection Practices on the Contamination of the Pig Carcasses
}

de Freitas Costa, Eduardo; Corbellini, Luis Gustavo; da Silva, Ana Paula Serafini Poeta; Nauta, Maarten

Published in:

Risk Analysis

Link to article, DOI:

$10.1111 /$ risa. 12753

Publication date:

2017

Document Version

Peer reviewed version

Link back to DTU Orbit

Citation (APA):

de Freitas Costa, E., Corbellini, L. G., da Silva, A. P. S. P., \& Nauta, M. (2017). A Stochastic Model to Assess the Effect of Meat Inspection Practices on the Contamination of the Pig Carcasses. Risk Analysis, 37(10), 18491864. https://doi.org/10.1111/risa.12753

\section{General rights}

Copyright and moral rights for the publications made accessible in the public portal are retained by the authors and/or other copyright owners and it is a condition of accessing publications that users recognise and abide by the legal requirements associated with these rights.

- Users may download and print one copy of any publication from the public portal for the purpose of private study or research.

- You may not further distribute the material or use it for any profit-making activity or commercial gain

- You may freely distribute the URL identifying the publication in the public portal 
1 A stochastic model to assess the effect of meat inspection practices on the contamination of

2 the pig carcasses

3

4 Eduardo de Freitas Costa*1; ${ }^{*}$ Luis Gustavo Corbellini ${ }^{1}$; Ana Paula Serafini Poeta da Silva ${ }^{1}$;

$5 \quad$ Maarten Nauta ${ }^{2}$

6 1: Laboratory of Veterinary Epidemiology (Epilab), Department of Preventive Veterinary

7 Medicine, Federal University of Rio Grande do Sul, Brazil

8 Address: Avenida Bento Gonçalves, n 9090, zip code 91540-000, Porto Alegre, RS, Brazil;

9 phone: +555133088025

10 2: Technical University of Denmark - National Food Institute

11 Mørkhøj Bygade, 19, Building G, DK-2860 Søborg, Denmark 


\section{Abstract}

The objective of meat inspection is to promote animal and public health, by preventing, detecting and controlling hazards originating from animals. With the improvements of sanitary level in pig herds the hazards profile has shifting and the inspection procedures have no longer targeting major foodborne pathogens (i.e., not risk-based). Additionally carcass manipulations performed when searching for macroscopic lesions can lead to cross-contamination. We therefore developed a stochastic model to quantitatively describe cross-contamination when consecutive carcasses are submitted to classic inspection procedures. The microbial hazard used to illustrate the model was Salmonella, the data set was obtained from Brazilian slaughterhouses and some simplifying assumptions were made. The model predicted that, due to cross-contamination during inspection, the prevalence of contaminated carcass surfaces increased from $1.2 \%$ to $95.7 \%$, whereas the mean contamination on contaminated surfaces decreased from 1 to -0.87 $\log \mathrm{CFU} / \mathrm{cm}^{2}$, and the standard deviations decreased from 0.65 to 0.19 . These results are explained by the fact that, due to carcass manipulations with hands, knives and hooks, including the cutting of contaminated lymph nodes, Salmonella is transferred to previously uncontaminated carcasses, but in small quantities. These small quantities can easily go undetected during sampling. Sensitivity analyses gave insight in the model performance and showed that the touching and cutting of lymph nodes during inspection can be an important source of carcass contamination. The model can serve as a tool to support discussions on the modernization of pig carcass inspection.

Keywords: Mathematical modeling, cross-contamination, carcass inspection 


\section{INTRODUCTION}

35 The main objective of meat inspection is to promote both animal and public health, by preventing, detecting and controlling microbial hazards originating from animals. ${ }^{(1)}$ Although no

37 precise definition about meat inspection procedures has been proposed, the Codex Alimentarius refers to two types of inspection. Ante-mortem examination consists of a clinical examination aimed at detection of non-healthy animals. Post-mortem examination consists of a pathological examination to identify potential hazards for human or animal health. ${ }^{(2)}$ Classically the inspection of pigs is done at all carcasses and the procedures are based on physical examinations,

42 like incisions, palpation and observation of the carcass, organs and lymph nodes, searching for macroscopic lesions, typical for classical zoonotic diseases. ${ }^{(3)}$

44 Although the recognition of animals as a source of pathogens to humans dates from prehistoric times, the current procedures were developed in Europe by Robert von Ostertag in $1900{ }^{(4)}$ They have an important role in controlling zoonotic diseases, mainly in places, where the production is

47 not done in an intensive production chain ${ }^{(5)}$ and, consequently, classic zoonosis are endemic.

48 The global livestock production systems have undergone an industrial revolution and the

49 production has shifted increasingly from smallholders to large-scale, industrial production chains. An increasing share of production comes from pigs and chickens that are more easily

51 adapted to large-scale industrial production than ruminants. ${ }^{(6)}$ In 2010 , even in developing countries, at least $50 \%$ of the herds in pork production are processed in integrated productions

53 systems. ${ }^{(7)}$

54 Nowadays, farms adhere to specific management requirements like all-in-all-out production, 55 controlled feed sources, indoor production, and a traceability system from the farm to the 56 slaughterhouse. ${ }^{(8)}$ As a consequence, hazards like parasites are getting rare in the industrial pork 
57 production chain. ${ }^{(8-10)}$ On the other hand, the intensification of the production brings changes in

58 the epidemiology and other microbial pathogens are emerging. ${ }^{(11)}$ Salmonella spp., Yersinia enterocolitica, Toxoplasma gondii and Trichinella spp. are identified as the most important

60 hazards to be covered by the meat inspection of swine carcasses. ${ }^{(5)}$

61 The interaction of these pathogens with the host and the environment raises some concerns about

62 the suitability of the classic inspection procedures. It demands structured control using all food

63 chain information to reach a risk-based inspection system. ${ }^{(12)}$ The modernization of meat

64 inspection has been extensively studied in Europe and since 2014, according to EC Regulation

$65219 / 2014$, the inspection of pig carcasses is visual-only for pig herds that have been reared in

66 integrated farm systems, doing palpation and incision when a lesion has been found after visual-

67 only inspection. ${ }^{(13)}$

68 In 2011 the European Food Safety Authority (EFSA) discussed the limitations of the meat

69 inspection system procedures, such as lymph node incision, in terms of consumer health

70 protection and stated that the classic procedures could increase the level of cross-contamination,

71 also for zoonotic pathogens. However, quantitative data on the impact of the inspection

72 procedures on cross-contamination are lacking and Hill et al. ${ }^{(14)}$ highlighted the need of studies

73 regarding the cross-contamination during the inspection procedures to support a risk-based

74 approach to meat inspection, which could improve the efficiency in dealing with public health

75 issues related to animal slaughter.

76 In this paper we describe a modelling approach to study the impact of meat inspection practices

77 on cross-contamination between pig carcasses and to provide insight in the potential effect of

78 these practices on the prevalence and concentration of pathogens on pig carcasses. Using

79 methods applied in quantitative microbiological risk assessment (e.g. Nauta et al. $)^{(15)}$, we aim to 
quantify the cross-contamination during meat inspection of pig carcasses via specific transfer

81 routes and to assess their relevance for the contamination of the carcasses. The model is set up as a generic model for cross-contamination during meat inspection and is applied to Salmonella transfer during inspection of pig carcasses in Brazil, because there is relevant data available from some large slaughterhouses in Brazil, and transfer of this pathogen from lymph nodes to the carcass surface has been considered a potential hazard. ${ }^{(16,17)}$ To illustrate the model, we focus on the point of the meat inspection identified as "CARCASS" by the Food and Agriculture

87 Organization of the United Nations (FAO). ${ }^{(18)}$ This point of inspection is not the same in all countries. In Brazil this inspection occurs after the carcass splitting and refers to inspection of specific parts of the pig carcass by looking, cutting and touching the skin, musculature, exposed bones, joints, tendon sheaths and serous membrane. It also includes several cuttings and palpation of the following lymph nodes: superficial inguinal, supramammary, external and

92 internal iliac, according to ordinance $711 / 1995$. $^{(19)}$

2. MATERIALS AND METHODS

\subsection{Conceptual model}

95 The basic structure of the model and the transfer routes considered are shown in Fig. 1. The model has a similar structure as the one developed by Nauta et $a l .{ }^{(15)}$ for broiler processing and is

97 based on classic meat inspection procedures, where a series of consecutively slaughtered carcasses are submitted to several manipulations, and cross-contamination between carcasses may occur via equipment (like cutting knives and hooks used to hang up the carcasses) and hands. Therefore, the knife, hands and hook were considered as the relevant components of the slaughter environment. As both the surface and organs of the pig may get in contact with hands and equipment, the carcass was separated in two components: the carcass surface and the 
103 possible organs evaluated during the inspection. Contact between the carcass (carcass surface

104 and organs) and the environmental components occurs on specific areas of the carcass surface

105 and the organs. The transfer of bacteria can happen from the environmental components to

106 carcass and from the carcass to environmental components.

107

108

109

110

111

112

113

114

115

116 117 the bacteria from the carcass (surface or organs) can only occur by the inspection activities that

Fig. 1. Schematic representation of the pig carcass inspection. Consecutive carcasses pass lead to cross-contamination via bacterial transfer from the environment to the carcass (arrow a) or from the carcass to the environment (arrow b). The arrows d represent the reduction in the concentration of the bacteria due to inactivation or removal.

The model only considers the carcass and the predefined environmental components as sources of bacteria, the influence of the air, carcass to carcass contact or other external factors are ignored. Also, bacterial growth during the inspection is excluded from the model. Removal of

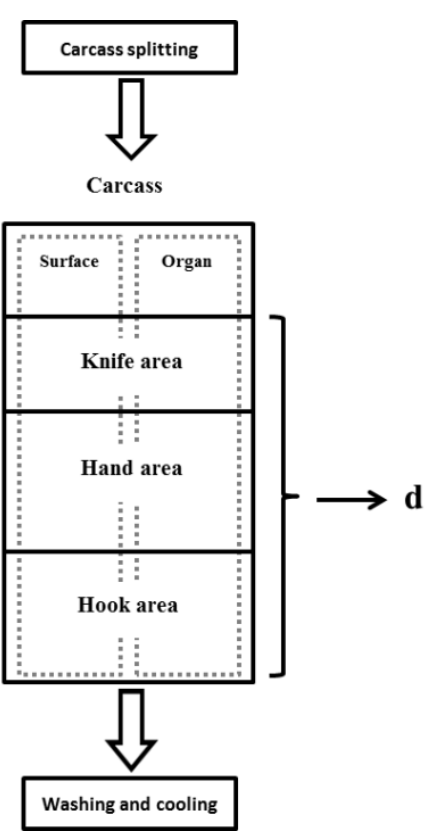
through the point of inspection and get in contact with the environmental components, which can are included in the model. Bacteria on the knife are frequently inactivated by putting the knife in 
119 hot water (i. e. $83^{\circ} \mathrm{C}$ ). Washing of hands and cleaning of the hooks are unusual or don't follow a 120 clear rule during meat inspection and have therefore not been considered.

121

122

\subsection{Mathematical model}

The model can be written as a system of five difference equations as given below (1). It describes the changes in the concentrations in the five components for consecutively slaughtered carcasses $i$, before inspection (stage S-1) and after inspection (stage $\mathrm{S}$ ). Variables are listed in Table 1. The upper cases letters represent variables, and lower case letters represent model parameters. Ae and $A c$ are used as index and refer to the different areas on carcass $(A e=$ knife $(\mathrm{K})$, hand $(\mathrm{H})$, hook $(\mathrm{G}))$ and different compartments of carcass $(A c=$ surface $(\mathrm{C})$ or organs $(\mathrm{O}))$.

$$
\left\{\begin{array}{l}
C_{i, S}=\sum_{A e \in\{K, H, G\}}\left(1-d_{C}\right)\left(1-b_{C, A e}\right)^{J_{i, C, A e}} C_{i,(S-1), A e}+E_{(i-1), A e}\left(1-\left(1-a_{A e, C}\right)^{J_{i, C, A e}}\right) \\
O_{i, S}=\sum_{A e \in\{K, H, G\}}\left(1-d_{O}\right)\left(1-b_{O, A e}\right)^{J_{i, O, A e}} O_{i,(S-1), A e}+E_{(i-1), A e}\left(1-\left(1-a_{A e, O}\right)^{J_{i, O, A e}}\right) \\
K_{i}=K_{(i-1)} \prod_{A c \in\{C, O\}}\left(1-a_{K, A c}\right)^{J_{(i-1), A c, K}}+\sum_{A c \in\{C, O\}} N_{i, A c}\left(1-d_{A c}\right)\left(1-\left(1-b_{A c, K}\right)^{J_{i, A c, K}}\right) \\
H_{i}=H_{(i-1)} \prod_{A c \in\{C, O\}}\left(1-a_{H, A c}\right)^{J_{(i-1), A c, H}}+\sum_{A c \in\{C, O\}} N_{i, A c}\left(1-d_{A c}\right)\left(1-\left(1-b_{A c, H}\right)^{J_{i, A c, H}}\right) \\
G_{i}=G_{(i-1)} \prod_{A c \in\{C, O\}}\left(1-a_{G, A c}\right)^{J_{(i-1), A c, G}}+\sum_{A c \in\{C, O\}} N_{i, A c}\left(1-d_{A c}\right)\left(1-\left(1-b_{A c, G}\right)^{J_{i, A c, G}}\right)
\end{array}\right.
$$

The variable $E_{i, A e}$ is the generic term to refer to the environment and the value of $A e$ for knife, hands or hook will be used according to the area modeled. Similarly, the variable $N_{i, A c}$ is a generic term to refer to the carcass surface or organs, according to the component $A c$ modeled. Organs will be referred to from here onward, as lymph nodes, because that is the most relevant organ evaluated during this specific inspection point. The variables are explained in the Table I. The numbers of contacts between the environmental components and the carcasses compartments are represented generically by $J_{i, A e, A c}$. When $A e=\mathrm{K}, \mathrm{H}, \mathrm{G}$ it refers to the number of contacts between the carcass and the knife, hand and hook respectively. These values are sampled from empirical distributions (see appendix A) and are assumed to affect either the 
142 surface or lymph nodes $(A c=\mathrm{C}, \mathrm{O})$ with equal probability $(50 \%)$. Also, the three areas on carcass

143 or lymph nodes are considered mutually exclusive: the worker does not touch the same carcass

144 area with his hands as the worker cuts with a knife or holds the carcass with the hook.

146 Table I. Overview of model variables (eq. 1): Each variable describes a quantity that is changing

147 for consecutive carcasses (with rank number $i$ ) and over the process steps S-1 (before) or S (after

148 inspection). Values before inspection are sampled from the indicated distributions and values

149 after inspection are calculated by the model

\begin{tabular}{|c|c|c|c|c|}
\hline Variable & Description & Distribution/function & Unit & Source \\
\hline$J_{i, A c, A e}$ & $\begin{array}{c}\text { Number of cuts, touches or hooking }(A e) \text { in the } \\
\text { surface or organs }(A c) \text { of the carcass } i\end{array}$ & Empirical $^{\#}$ & Count & Appendix A \\
\hline $\log _{10}\left[C_{i,(S-1)}\right]$ & $\begin{array}{l}\text { Salmonella concentration on the carcass surface } i \\
\text { before inspection (S-1) on contaminated carcass. }\end{array}$ & $\operatorname{Normal}(-5.4 ; 2.2)^{\ominus \#}$ & $\log _{10} \mathrm{CFU} / \mathrm{cm}^{2}$ & Appendix B \\
\hline $\operatorname{PrevC}_{i(S-1)}$ & $\begin{array}{l}\text { Status of carcass surface contamination on the } \\
\text { carcass } i \text { before inspection }(S-1)\end{array}$ & $100 \%$ & Positive/Negative & Appendix B \\
\hline$C_{i,(S-1)}$ & $\begin{array}{l}\text { Salmonella counts on the carcass surface } i \text { before } \\
\text { inspection (S-1) on contaminated carcass. }\end{array}$ & $\operatorname{Poisson}\left(\left[C_{i(S-1)}\right] e a_{A e} J_{i, C, A e}\right)$ & $\mathrm{CFU}^{\# \#}$ & $\begin{array}{c}\text { Calculation, see } \\
\text { Table } 2\end{array}$ \\
\hline$\left[O_{i,(S-1)}\right]$ & $\begin{array}{l}\text { Salmonella concentration in organs (lymph nodes) } \\
i \text { before inspection }(S-1) \text { in contaminated lymph } \\
\text { nodes. }\end{array}$ & Triangular $(0.1 ; 1 ; 100)$ \# & $\mathrm{CFU} / \mathrm{cm}^{2}$ & Assumption \\
\hline$O_{i,(S-1)}$ & $\begin{array}{l}\text { Salmonella counts in organs (lymph nodes) } i \\
\text { before inspection }(S-1) \text { in contaminated lymph } \\
\text { nodes. }\end{array}$ & $\operatorname{Poisson}\left(\left[O_{i(s-1)}\right] e a_{A e} J_{i, O, A e}\right)$ & $\mathrm{CFU}^{\# \#}$ & $\begin{array}{c}\text { Calculation, see } \\
\text { Table } 2\end{array}$ \\
\hline $\operatorname{PrevO}_{i,(S-1)}$ & $\begin{array}{l}\text { Status of organs contamination in the carcass } i \\
\text { before inspection ( } S \text {-1) (i.e., carrying Salmonella } \\
\text { in lymph nodes) }\end{array}$ & Bernoulli(14.1\%) & Positive/Negative & (11) \\
\hline$K_{i}$ & $\begin{array}{l}\text { Amount of Salmonella on knife by the carcass } i \\
\text { after inspection }\end{array}$ & Model & $\mathrm{CFU}$ & Calculation \\
\hline$H_{i}$ & Amount of Salmonella on hands by the carcass $i$ & Model & $\mathrm{CFU}$ & Calculation \\
\hline
\end{tabular}




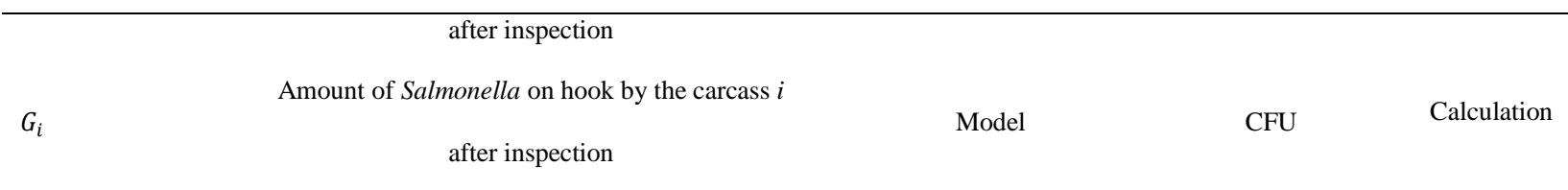

${ }^{\#}$ Distribution expressing variability between carcasses $i ;{ }^{\ominus}$ Parameters $\left(\mu, \sigma\right.$ and $\left.\operatorname{Prev}_{i(s-1)}\right)$ were fitted according a zero inflated normal distribution by Maximum Log likelihood estimation method (Appendix B); ${ }^{\#}$ CFU per inspected area.

The model was implemented as a Monte Carlo simulation model. Transfers were described as binomial processes taking into account the successive contacts between environment and carcass, as explained in appendix C. For example, in the first term in the equations considering the carcass, $\left(1-d_{C}\right)\left(1-b_{C, A e}\right)^{J_{i, C, A_{e}}}$ is the fraction of the number of Salmonella that are not lost by removal $(d)$ and not transferred from the carcass, to the environment on different areas, indicated by the index $A e$ (knife area, hand area, and hook area). The second term is $\left(1-\left(1-a_{A e, C}\right)^{J_{i, C, A e}}\right)$, the fraction of the number of Salmonella received from the environment indicated by the index Ae (knife, hand and hook) to the carcass and can be derived as explained in appendix $\mathrm{C}$.

In the last three equations, modeling the environmental components, using the knife as example, the first term: $K_{(i-1)} \prod_{A c \in\{c, O\}}\left(1-a_{K, A c}\right)^{J_{(i-1), A c, K}}$ concerns the Salmonella that are not transferred from the knife to the carcass $(i-1)$ on different compartments indexed by $A c$ (surface and lymph nodes). The second term $\left(1-d_{A c}\right)\left(1-\left(1-b_{A c, K}\right)^{J_{i, A c, K}}\right.$ indicates the Salmonella received from the carcass indicated by the index $A c$ (surface or lymph nodes). The variables $C_{i,(S-1)}$ and $O_{i,(S-1)}$ represent the counts of Salmonella before the inspection and describe the variability between inspected carcass surfaces and organs respectively. To account for the random spatial distribution of cells over the inspected area, a Poisson distribution was used. In order to assess the true prevalence, the variables $C_{(i-1), S}$ and $O_{(i-1), S}$ were multiplied by the positive/negative 
171 status (1 or 0) of carcass surface contamination $\operatorname{Prev}_{i,(S-1)}$ and lymph nodes $\operatorname{Prev}_{i,(S-1)}$,

172 both sampled from Bernoulli distributions.

173 The transfer parameters $a, b$ are used in combination with the index $A e$ or $A c$ according to the 174 area on the carcass or the environmental components modeled. For instance when the parameter $175 a$ is used with index $A e$, it refers to the probability of transfer of a CFU from the environment 176 according index Ae used (knife, hand or hook) to the carcass (C) or lymph nodes (O). The 177 removal parameter $d$, is indexed by $A c$ because detection or reduction are accounted only on 178 carcass surface and lymph nodes. Table II provides an overview of the parameters used in the 179 model.

180 Counts of Salmonella were expressed in CFU and the outputs were calculated for the inspected 181 areas $\left(\mathrm{CFU} / \mathrm{cm}^{2}\right)$ and then transformed to natural logarithm (presented here as "log"),

182 considering only the contaminated carcasses (because $\log (0)$ is not defined). When a carcass has 183 not been submitted to any contact with the environment by hands, knife or hook, the carcass was 184 considered as not inspected and, consequently, the concentration on inspected area is assumed to 185 be the same as before (S-1). Also the probability of inactivation or removal on carcass or in 186 lymph nodes $\left(d_{C}\right.$ or $\left.d_{O}\right)$ are underlying assumed to be zero. The analyses were done using $187 @$ @isk 6.2.1 (Palisade) for Excel with 10000 iterations using 500 and 100 consecutively 188 processed carcasses in two separate simulations. These numbers were chosen to approximate 189 realistic numbers of pigs slaughtered in a slaughter line per shift of two hours (i.e. 350 190 carcasses/hour), whilst keeping the model manageable and restricting the running time.

192 Table II. Parameters used to illustrate the dynamics of the model. The indices $A e$ and $A c$ are 193 given by the initials of environment and carcass compartments respectively 


\begin{tabular}{|c|c|c|c|c|}
\hline Parameters & Description & Unit & Value & Source \\
\hline$\overline{a_{K, C}}$ & Transfer probability knife-carcass & $\%$ & 0.17 & (21) \\
\hline$a_{K, O}$ & Transfer probability knife-lymph nodes & $\%$ & 0.17 & (21) \\
\hline$a_{H, C}$ & Transfer probability hand-carcass & $\%$ & 0.21 & (22) \\
\hline$a_{H, O}$ & Transfer probability hand-lymph nodes & $\%$ & 0.21 & (22) \\
\hline$a_{G, C}$ & Transfer probability hook-carcass & $\%$ & 0.17 & (21) \\
\hline$a_{G, O}$ & Transfer probability hook-lymph nodes & $\%$ & 0.17 & (21) \\
\hline$b_{C, K}$ & Transfer probability carcass-knife & $\%$ & 0.17 & (21) \\
\hline$b_{C, H}$ & Transfer probability carcass-hand & $\%$ & 3.1 & (22) \\
\hline$b_{C, G}$ & Transfer probability carcass-hook & $\%$ & 0.17 & (21) \\
\hline$b_{O, K}$ & Transfer probability lymph nodes-knife & $\%$ & 0.17 & (21) \\
\hline$b_{O, H}$ & Transfer probability lymph nodes-hand & $\%$ & 0.21 & (22) \\
\hline$b_{O, G}$ & Transfer probability lymph nodes-hook & $\%$ & 0.17 & (21) \\
\hline$e a_{A e}$ & Environmental components area & & & \\
\hline$A e=H$ & Area of touch $\left(\mathrm{cm}^{2}\right)$ & $\mathrm{cm}^{2}$ & 150 & Assumption* \\
\hline$A e=G$ & Area of hook $\left(\mathrm{cm}^{2}\right)$ & $\mathrm{cm}^{2}$ & 1 & Assumption* \\
\hline$A e=K$ & Area of cut $\left(\mathrm{cm}^{2}\right)$ & $\mathrm{cm}^{2}$ & 10 & Assumption* \\
\hline $\mathrm{ck}$ & Probability of changing the knife & $\%$ & 90 & $\begin{array}{c}\text { Assumption (based on } \\
\text { observations) }\end{array}$ \\
\hline
\end{tabular}

$194 *$ Estimates for the medium size of these areas, author's best guess.

\section{$195 \quad 2.3$ Sensitivity analysis}

196 First, the baseline model was built with the parameter values indicated in Tables 1 and 2. Next,

197 two types of sensitivity analyses were performed. First, several univariate analyses were done to

198 assess the impact of parameters on the model outputs. To avoid unrealistic values we used a

199 range of values between each parameter baseline value $(y)$ and realistic minimum and maximum 
200 values of the parameter considered $\left(y^{-}\right)$and $\left(y^{+}\right)$respectively (Appendix D). To assess the

201 impact of ranges of input values, above and below the baseline we applied:

$202 f\left(x ; y, y^{-}, y^{+}\right)= \begin{cases}y+\left(y-y^{-}\right) x, & \text { for } x<0 \\ y-\left(y-y^{+}\right) x, & \text { for } x \geq 0\end{cases}$

203 witch runs from minimum to maximum when $x$ runs from -1 to 1 and meets the baseline when

$204 x=0$. The univariate analyses were ran with 10000 iterations using 100 carcasses. Based on the

205 univariate results, nine scenarios were submitted to multivariate analyses (Appendix E) and

206 simulated with 10000 iterations using 500 carcasses.

$207 \quad 2.4$ Data sources

208 The data on the carcass surface contamination were obtained from da Silva et al. ${ }^{(20)}$ These

209 authors collected carcass surface swabs in three Brazilian commercial slaughterhouses. Data

210 regarding the lymph nodes prevalence where obtained from 12 cohorts representing finishing

211 herds located in the state of Santa Catarina, Brazil. ${ }^{(11)}$ These herds belong to an integrated system

212 responsible for approximately $7 \%$ of all Brazilian pork production in 2007. Manipulation data

213 were observed during two weeks in March 2015 in a large Brazilian pig slaughterhouse

214 dedicated to exportation. 778 inspection procedures were counted during this period, of which

215290 in the inspection point "CARCASS". The numbers of manipulations were recorded in a

216 database. Although no data regarding transfer probability in slaughterhouse environment could

217 be found, results from Kim et al. ${ }^{(21)}$ and Hong and $\mathrm{Bahk}^{(22)}$, provide transfer probabilities

218 between hands and pork and knife and pork, respectively. We have not found suitable

219 concentration data for Salmonella in lymph nodes, the values used were based on estimates of

220 the authors.

221 3. RESULTS

$222 \quad 3.1$ Baseline and distributions 
223 In the baseline model, the mean of the mean concentrations $(\mu)$ and the mean prevalence were

224 determined for two independent simulations with 500 and 100 consecutive carcasses, over 10000

225 iterations. As the mean concentration is the mean of logs, only contaminated carcasses are

226 included in the calculations. The results are summarized and given in Table III. The mean

227 concentration on inspected areas of the contaminated carcass surfaces is decreasing after

228 inspection procedures, from 1 to $-0.87 \log C F U / \mathrm{cm}^{2}$. Standard deviations of the means decrease

229 as well, from 0.65 to 0.2 . The reason is that many more carcass surfaces are getting contaminated

230 by cross-contamination, resulting in a large number of carcasses (i. e. a prevalence difference of

23194.6 percentage points) contaminated with lower concentrations. Consequently the variability is

232 decreasing (See Fig. 2).

233 Table III. Outputs for inspected areas of carcass surface and lymph nodes before and after

234 inspection procedures in model simulations with 500 and 100 carcasses. The mean $(\mu)$ and

235 standard deviation $(\sigma)$ are those of the mean values for the contaminated inspected carcass areas

236 among the 500 or 100 simulated carcasses; the prevalence is the mean prevalence after 10000

237 iterations

\begin{tabular}{|c|c|c|c|c|c|c|}
\hline & \multicolumn{3}{|c|}{500 carcasses } & \multicolumn{3}{|c|}{100 Carcasses } \\
\hline & $\mu(\sigma) \log C F U / \mathrm{cm}^{2}$ & Prevalence $\% \#$ & $\begin{array}{l}\text { CFU in the } \\
\text { system }^{\# \#}\end{array}$ & $\mu(\sigma) \log C F U / \mathrm{cm}^{2}$ & Prevalence $\%^{\#}$ & $\begin{array}{c}\text { CFU in the } \\
\text { system }^{\# \#}\end{array}$ \\
\hline Surface before & $1(0.65)$ & 1.2 & $2.6^{*} 10^{5}$ & $1(1.22)$ & 1.2 & $4.2 * 10^{4}$ \\
\hline Surface after & $-0.87(0.2)$ & 95.8 & $3.7 * 10^{5}$ & $-1.6(0.47)$ & 92 & $5.2 * 10^{4}$ \\
\hline LN before & $3.17(0.13)$ & 22.2 & $2.3 * 10^{6}$ & $3.17(0.3)$ & 23.8 & $4.6 * 10^{5}$ \\
\hline LN after & $0.08(0.2)$ & 96.7 & $2.1 * 10^{6}$ & $-0.41(0.51)$ & 93.9 & $4.1 * 10^{5}$ \\
\hline
\end{tabular}


238 LN=Lymph node; " The prevalence refers to at least one cell on inspected area; ${ }^{\# \#}$ arithmetic 239 mean (over 10000 iterations) of the total number of Sallmonella on carcasses surface and lymph 240 nodes (i. e. whole carcass) in all simulated areas per iteration.
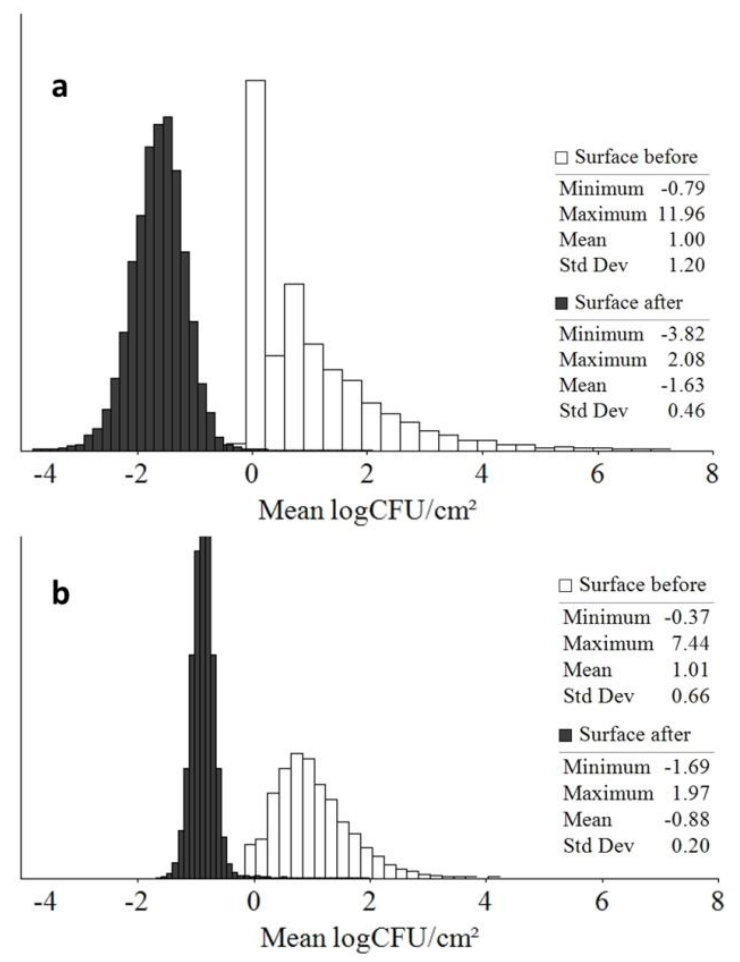

243 Fig. 2. Distribution of mean carcasses surface contamination $\left(\log \mathrm{CFU} / \mathrm{cm}^{2}\right)$ considering only

244 contaminated carcasses before and after inspection in two separated simulations with 100 (a) and 245500 (b) carcasses.

247 For the lymph nodes the effects of the inspection procedures on the mean and prevalence are 248 similar to those observed in the carcass surface (i.e. decrease and increase respectively), but the 249 standard deviation increases after inspection. Although the results suggest a reduction in mean 250 carcass surface contamination, after inspection, the sum of the numbers of Salmonella ("CFU in 251 the system") is increasing on the carcass surface and decreasing in the lymph nodes. The reason 
252 is that the geometric mean (mean of $\log \mathrm{CFU}$ ), which only can includes values larger than zero

253 (i.e. contaminated carcasses), should not be interpreted as an arithmetic mean. As the model does

254 not assume any growth, the only sources of contamination are the carcasses entering into the

255 slaughterhouse and therefore the results indicate a flow of contamination from the lymphatic

256 tissue to the surface by inspection procedures.

257 Results differ depending on the number of simulated carcasses. With a lower number of

258 carcasses, the variation in mean concentrations sampled from the zero inflated Poisson

259 Lognormal is larger. For example, with the prevalence $1.2 \%$, the probability that the

260 concentrations in all 100 carcass surfaces are zero is $(1-0.012)^{100}=30 \%$, for 500 carcass surfaces

261 it is $(1-0.012)^{500}=0.24 \%$ (compare Fig $2 \mathrm{a}$ and $2 \mathrm{~b}$ ). The peaks in figure 2a before inspection

262 reflect the sampling of 1 and 2 positive carcasses, with the variability in concentrations around it.

263 Differences between distributions are smaller when considered after inspection, because more

264 carcass surfaces are contaminated. Hence, the number of carcasses used in the analysis is

265 relevant and the number of carcasses used to run the model should be realistic. Still, very large

266 numbers of carcasses slow down the calculations considerably.

$267 \quad 3.2$ Univariate sensitivity analyses

268 Of the 23 parameters analyzed (see appendix D) seven had a significant impact on the output

269 mean of the means $(\mu)$ and four on the mean prevalence. Here, the impact is considered

270 significant if the mean output values in the sensitivity analysis fall out of the range correspondent

271 to $2.5^{\text {th }}$ and $97.5^{\text {th }}$ percentiles of the distribution describing the variability between model

272 iterations in the mean $\mu$ from -2.57 to $-0.83 \operatorname{logCFU} / \mathrm{cm}^{2}$ and prevalence $81-98 \%$. As shown in

273 Fig. 3 the mean concentration of carcass surface contamination before inspection $\left[C_{i,(S-1)}\right]$ and

274 its standard deviation had an important effect on the surface contamination after inspection 
275 procedures. The mean after inspection increased from -1.6 to $9.07 \log \mathrm{CFU} / \mathrm{cm}^{2}$ on the inspection area when the load of Salmonella on carcass surfaces before inspection approaches the maximum

277 value $\left(2 \log _{10} \mathrm{CFU} / \mathrm{cm}^{2}\right.$ compared to -5.4 in the baseline). The same effect cannot be seen when

278 mean and standard deviation are decreased below the baseline. Changes in lymph nodes

279 contamination, by changing the maximum value of the triangular distribution used in $\left[O_{i,(S-1)}\right]$

280 from 100 to $1000 \mathrm{CFU} / \mathrm{cm}^{2}$, increased the mean to $0.54 \log \mathrm{CFU} / \mathrm{cm}^{2}$, and decreases it to -3.6

$281 \log \mathrm{CFU} / \mathrm{cm}^{2}$ when the parameter is reduced to $10 \mathrm{CFU} / \mathrm{cm}^{2}$. Also the prevalence of animals

282 carrying Salmonella in lymph nodes had an important effect by reducing the mean contamination

283 to $-4.3 \log \mathrm{CFU} / \mathrm{cm}^{2}$ and increasing it to $-0.7 \operatorname{logCFU} / \mathrm{cm}^{2}$ compared to the baseline $(-1.6$

$\left.284 \log \mathrm{CFU} / \mathrm{cm}^{2}\right)$.

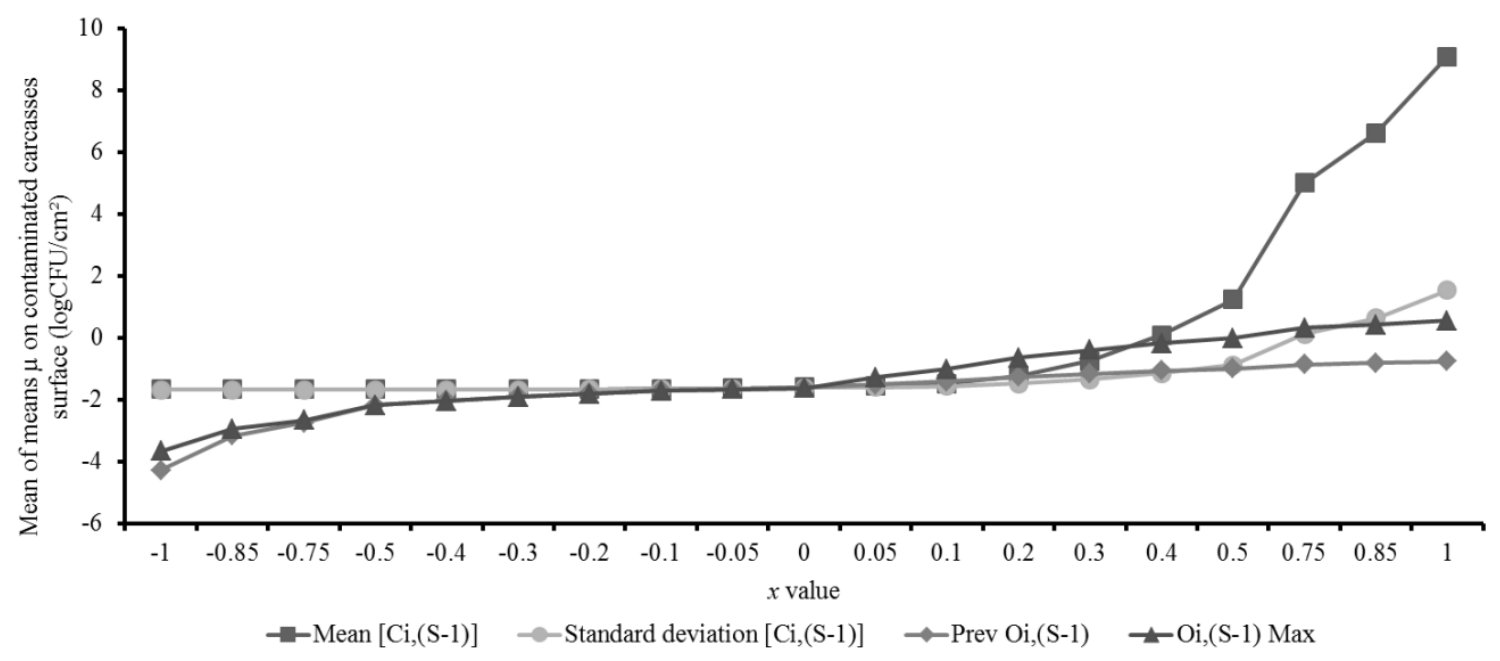

Fig. 3. Mean of the means $(\mu) \log C F U / \mathrm{cm}^{2}$ in in function of different $x$ values regarding the variables mean $\left[\mathrm{C}_{i,(\mathrm{~S}-1)}\right]$, standard deviation of $\left[\mathrm{C}_{i,(\mathrm{~S}-1)}\right]$, Prev $\mathrm{O}_{i,(\mathrm{~S}-1)}$ and maximum $\left[\mathrm{O}_{i,(\mathrm{~S}-1)}\right]$.

Fig. 4 shows how changes in transfer probabilities affect the mean contamination on the carcass surface. If the transfer probability from hands to lymph nodes $\left(a_{H, O}\right)$ decreases to $0 \%$ using $x=-$ 
292 the hands and a subsequent increase of transfer to the carcass surface, leading to a small increase 293 of the mean to approximately $-1.45 \log C F U / \mathrm{cm}^{2}$. But when the same parameter is increased, the 294 mean decreases because the cells transferred to the lymph nodes can no longer be transferred to 295 the carcass surface.

296

297

298

299

300

301

302

303

304

305

306

307

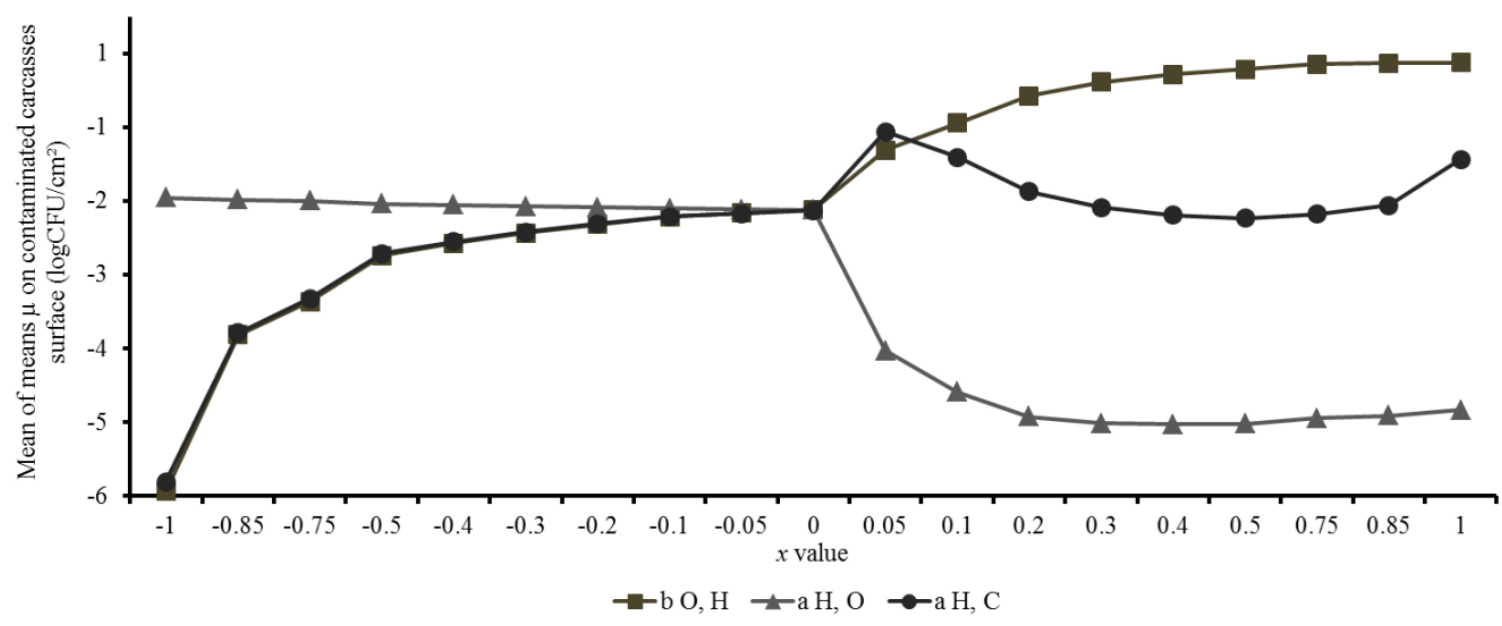

Fig. 4. Mean of the means $(\mu) \log C F U / \mathrm{cm}^{2}$ as a function of different $x$ values regarding the parameters $\left(b_{O, H}\right),\left(a_{H, O}\right)$ and $\left(a_{H, C}\right)$.

Both transfer probabilities from the lymph node to hand $\left(b_{O, H}\right)$ and to carcass by the hand $\left(a_{H, C}\right)$, show similar results below the baseline, but $b_{O, H}$ keeps increasing the mean until $x$ approaches $1\left(b_{O, H}=100 \%\right)$. On the other hand, $a_{H, C}$ has a peak when $x$ is close to 0.05 . There is a peak because, at some point, the transfer from hand to carcass gets so large that the concentration on the hands gets too low. Once a large number of bacteria are transferred to the first carcasses only a few bacteria are transferred to the subsequent carcasses, reducing the mean concentration without relevant effects on prevalence (Fig. 5). As the $a_{H, C}$ keeps increasing, bacteria get even more concentrated on the first carcasses after hands contamination, reducing 
prevalence compared to the situation with a lower $a_{H, C}$ (Fig. 5). As the mean log can be

310 contaminated carcasses leads to increases of the mean $\left(\log C F U / \mathrm{cm}^{2}\right)$ when the $x$ increases for the

311 variables $a_{H, C}$ and $a_{H, O}$.

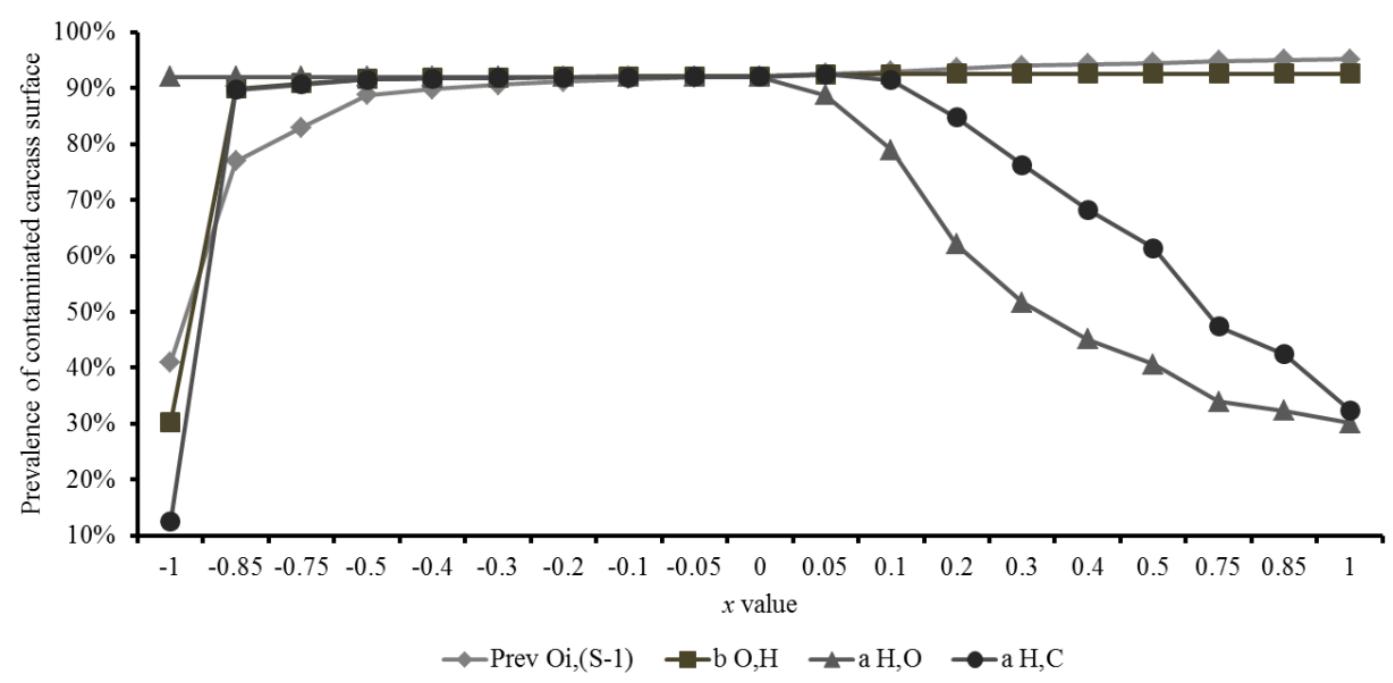

313 Fig. 5. Prevalence of carcass surface contamination as a function of different $x$ values regarding

314 the variable Prev $\mathrm{O}, i(\mathrm{~S}-1)$ and parameters $\left(b_{O, H}\right),\left(a_{H, O}\right)$ and $\left(a_{H, C}\right)$.

Fig. 5 shows the effects of tested parameters on prevalence after inspection. The effect of

317 reduction of $\operatorname{Prev}_{i,(\mathrm{~S}-1)}, b_{O, H}$ and $a_{H, C}$ to zero (minimum values, when $\mathrm{x}=-1$ ) leads to a reduction

318 of the surface prevalence to approximately $40 \%, 29 \%$ and $12 \%$ respectively, whereas reductions

319 in $a_{H, O}$ do not seem to affect the surface prevalence. When the values of the transfer parameters

$320 a_{H, O}$ and $a_{H, C}$ are increased, a reduction of the prevalence is observed. The reduction in the

321 number of positive carcasses leads to an increase of the mean log surface contamination as

322 observed in Fig. 4, as this can be calculated for positive carcasses only.

$323 \quad 3.3$ Multivariate sensitivity analyses 
324 Table IV shows the mean of the means $(\mu) \log C F U / \mathrm{cm}^{2}$, its standard deviation $(\sigma)$ and mean 325 prevalence on carcass surface 'before' and 'after' inspection in the multivariate sensitivity 326 analyses. The first scenario shows the baseline for comparison proposes. The second and third 327 scenarios present a stress analysis to verify the model performance. As expected, when transfer 328 probabilities are set to zero, the outputs 'before' and 'after' were the same. Also, the absence of 329 sources of contamination results in a completely uncontaminated scenario after inspection, 330 meeting the null contamination set by the parameters.

331 Table IV. Scenarios used in multivariate analyses to test the effect of different variables 332 combination on mean of the means $(\mu) \log \mathrm{CFU} / \mathrm{cm}^{2}$ its standard deviation $(\sigma)$ and mean 333 prevalence of contaminated carcass surface before and after inspection

\begin{tabular}{|c|c|c|c|c|}
\hline \multirow[b]{2}{*}{ Scenario } & \multicolumn{2}{|c|}{$\mu(\sigma) \log \mathrm{CFU} / \mathrm{cm}^{2}$} & \multicolumn{2}{|c|}{ Prevalence \% } \\
\hline & before & after & before & after \\
\hline Baseline & $1(0.65)$ & $-0.87(0.2)$ & 1.2 & 95.8 \\
\hline No transfer & $1(0.65)$ & $1(0.65)$ & 1.2 & 1.2 \\
\hline No contamination (S-1) & - & - & 0 & 0 \\
\hline Only carcass (S-1) & $1(0.65)$ & $-5.08(0.89)$ & 1.2 & 43.9 \\
\hline Only LN (S-1) & - & $-0.93(0.18)$ & 0 & 95.7 \\
\hline Hand influence high mean on $\log _{10}\left[C_{i,(S-1)}\right]$ & $1.8(0.28)$ & $0.64(0.82)$ & 11.3 & 96.7 \\
\hline Hand influence high standard deviation & $2.6(0.52)$ & $0.12(1.56)$ & 6.2 & 96.4 \\
\hline
\end{tabular}


Hand Influence high $\left[O_{i,(s-1)}\right]$

Hand Influence high $\operatorname{PrevO}_{i,(S-1)}$
$1(0.65)$
$1.31(0.18)$

$0.5(0.11)$
1.2

1.2
97.3

97.4
334

When only the carcass surface was included as the source of Salmonella, an important difference could be found as both the level of surface contamination and prevalence after inspection were drastically reduced compared to the baseline. The influence of high transfer probability involving the hands and carcass, by increasing the parameters $a_{H, C}, b_{C, H}$ (appendix E) tested together with a higher initial concentration on contaminated carcass surfaces $\left(\log _{10}\left[C_{i,(S-1)}\right]=-3 \log _{10} \mathrm{CFU} / \mathrm{cm}^{2}\right)$, increased the mean from -1.6 to $0.64 \log \mathrm{CFU} / \mathrm{cm}^{2}$ and the mean prevalence to $96.7 \%$. The influence of high transfer probability involving the hands and carcass was also tested with an increase of variability of contamination on carcass surface. It resulted in an increase of carcass surface contamination because surface contamination $(\mathrm{S}-1)$ is entered in the model as $\log _{10}$, so increases in variability affect the expected value, as the arithmetic mean of $\mathrm{C}_{\mathrm{is}}$ equals $10^{\left(\mu+\left(\frac{1}{2} \log (10) \sigma^{2}\right)\right.}$ and the transfer of bacteria acts as a factor of quantity and not of the logquantity.

Also, the influence of high transfer probability involving hands and carcass was tested with a higher concentration of Salmonella in lymph nodes (mean=337 CFU/ $\mathrm{cm}^{2}$ ) and a high frequency of animals carrying Salmonella in lymph nodes (100\%). The increase in lymph nodes contamination $\mathrm{O}_{\mathrm{i},(\mathrm{S}-1)}$ had an important effect on the mean, changing it from -0.88 to 1.31 $\log \mathrm{CFU} / \mathrm{cm}^{2}$. Changings in Prev $\mathrm{O}_{\mathrm{i},(\mathrm{S}-1)}$ also increased the surface contamination and prevalence after inspection. The mean on surface contamination increased to $0.55 \log \mathrm{CFU} / \mathrm{cm}^{2}$ and the prevalence to $97.4 \%$. 


\section{DISCUSSION}

355 We developed a generic mechanistic model to assess the effect of cross-contamination during pig 356 carcass inspection, which can be applied to different hazards for different inspection practices.

357 Its performance has been studied for one inspection step, using a Brazilian data set on 358 Salmonella contamination and some parameters assumptions. The results allow us to draw 359 conclusions on the potential impact of the cross-contamination during meat inspection, but are not necessarily considered representative for the impact of the whole inspection process of pig carcasses and the related policies in Brazil, since it deals with only one point of inspection. To do

362 so, all the three points in Brazilian inspection of pig carcasses should be included and data about 363 the contamination in lymph nodes should be also used as an input. Corbellini et al. ${ }^{(23)}$ have 364 reported the importance of variability between different days and slaughterhouses on Salmonella 365 contamination in Brazil and this information is essential for a realistic assessment of the impact 366 of meat inspections practices in the country.

367 With the inputs used, the model showed that the meat inspection leads to a redistribution of Salmonella over the carcasses, which implies that many more carcasses become contaminated,

369 but with (very) low numbers of bacteria. In terms of prevalence and concentrations we found an 370 increase in the surface contamination prevalence with more than 90 percentage points through 371 the inspection process and, due to the increase in the number of contaminated carcasses, a 372 decrease in the mean of the mean log concentrations in contaminated carcasses. The cutting of 373 the lymph nodes during inspection plays an important role, as it adds Salmonella to the carcass 374 surface areas that were not present on carcass surfaces before inspection. Overall, the model 375 shows that the conduction of meat inspection can lead to a spread of Salmonella from the 376 lymphatic tissue to carcass surface, decreasing the differences between the surface contamination 
of different carcasses.

378 Note that the baseline depicts a scenario of high lymph node contamination, and although we 379 have no data about lymph nodes contamination, prevalence studies have shown that this is not 380 always realistic. ${ }^{(24-26)}$ The phenomena described here meet results from previous research on the 381 effect of carcass manipulation on carcass surface contamination by Salmonella, where the 382 importance of lymphatic tissue manipulation has been observed in herds with a high number of 383 pigs harboring the bacteria in lymph nodes. ${ }^{(17,24)}$ If the model would be applied to obtain realistic 384 estimates, the user should adjust parameter values and distributions to their observations. For 385 example, variation in the prevalence of contaminated pigs or contaminated lymph nodes entering 386 in slaughterhouse can be found as a function of season, slaughterhouse and slaughter day. ${ }^{(27-29)}$

387 In the sensitivity analyses, equation (2), used to standardize the domain, can result in a sudden 388 changing on the value of the parameters (i.e. $f(x))$ when $x=0$ (e.g. Fig 4.). It occurs because the 389 derivative $f^{\prime}(x)$ is $\left(y-y^{-}\right)$for $\mathrm{x}<0$ and $\left(y-y^{+}\right)$for $\mathrm{x} \geq 0$, so when $\left(y-y^{-}\right) \neq\left(y-y^{+}\right)$the 390 equation has two different slopes below and above the baseline $\mathrm{x}=0$. As the distances in the 391 image (i.e. $\Delta f(\mathrm{x}))$ are not the same, this can give the impression that the effect is stronger on one 392 side than the other (Fig. 4 and 5). As an example when the bacterial transfer baseline is $0.17 \%$, 393 (i. e. far from the 50\%, center of this domain) with minimum and maximum values as 0 and 1 394 respectively, applying equation (2) we obtain a transfer value of approximately $11 \%$ when $x=0.1$ 395 and $0.1 \%$ when $\mathrm{x}=-0.1$.

396 The multivariate sensitivity analysis (table IV) showed that, when the lymph nodes were 397 considered to be uncontaminated (i.e only the carcass surface was a source of contamination), the 398 surface contamination after inspection was much lower than in the baseline. Also, the mean (SD) $399 \log \mathrm{CFU} / \mathrm{cm}^{2}$ decreased to $-5(0.89)$ and in such a scenario a large number of positive carcasses 
400

401

402

403

404

405

406

407

408

409

410

411

412

413

414

415

416

417

418

419

420

421

422

would be below the limit of detection $\left(-4 \log \mathrm{CFU} / \mathrm{cm}^{2}\right)^{(20)}$, so the observable prevalence would only be $5 \%$ instead of $44 \%$. On the other hand, when only the lymph nodes are considered as source of bacteria, the results were kept similar to the baseline, indicating that the effect of lymph nodes inspection dominated the surface carcass contamination.

When only considering the prevalence, the results obtained here may seem to be alarming and unrealistic, because the increase in more than 90 percentage points is very large and it is not observed in prevalence studies, which give values like $24 \%{ }^{(11)}$ and $14 \%{ }^{(20)}$ Although these prevalence results were obtained in Brazilian slaughterhouses before chilling, no inactivation step is used in Brazil between the carcass inspection and the chilling. A reason that observed prevalences are so much lower than predicted by the model may be the localization of the contaminating bacteria, which is restricted to areas manipulated by the inspection workers. These may not correspond with areas sampled when these prevalence studies were performed.

According to Jongenburger et al. ${ }^{(30)}$ batches with localized bacterial concentration reduce the observed prevalence with a factor $l$, derived from the relative size of the contaminated areas compared to the whole surface (see Appendix F). Another issue could be related with the difference between the measured prevalence (observed frequency of carcasses positive for Salmonella in the microbial test) and the modeled prevalence, which refers to the true prevalence, that is carcasses with one or more CFU. Although this difference must to be taken into account, in our simulations the mean (SD) contamination on carcass surfaces after inspection was $-0.8(0.2) \log \mathrm{CFU} / \mathrm{cm}^{2}$ (Figure 2) which assuming a normal distribution, means that none carcasses will have a level of contamination below the limit of detection (LOD=-4 $\left.\log \mathrm{CFU} / \mathrm{cm}^{2}\right)^{(20)}$ (calculations not shown). Hence, it is expected that the modeled and measured prevalences are expected to be the same in our simulations. 
423 The carcass inspection is one of the many activities in the whole pork production and the model

424 does not allow us to access the impact of the inspection procedures when compared to more

425 extensive dressing activities. In this sense studies as conducted by Swart et al. ${ }^{(31)}$ describing

426 Salmonella concentrations at different stages of the slaughterhouse process should be conducted.

427 Also no direct conclusion can be drawn regarding the impact of inspection procedures on the

428 number of human salmonellosis cases. A quantitative microbial risk assessment (QMRA) could

429 help to answer such question, since the outputs of this model can be applied to assess the impact

430 of the cross-contamination on human exposure. ${ }^{(32)}$

431 The present model is a tool to account for cross-contamination during the carcass inspection. The

432 purpose of the model is to capture the essential dynamics, and therefore the right balance

433 between reality/complexity and simplicity is important. ${ }^{(33)}$ Simplifying assumptions about the

434 inspection process are for example that we choose to give an equal probability of handling the

435 carcass surface and lymph nodes and that the inspection workers are equally capable to run the

436 inspections and treat each carcass randomly. Only knife, hand and hook are modelled, because

437 procedures regarding the use of these three components are more standardized and easier to

438 quantify. In general, the effect of direct contact (hand, knife) is more important to carcass

439 contamination than other potential sources of contamination. ${ }^{(34,35)}$

440 Also, in this model, only carcass surface and lymph nodes are considered as sources of

441 contamination. Regarding the meat inspection procedures, this can be considered a realistic

442 approach because viscera, like intestines, are cut and manipulated, usually, in another step of the

443 slaughter process $^{(2)}$. Although some adaptations of the model may be necessary, the model is

444 generic enough to deal with different hazards and inspection processes.

445 Several authors have reported different approaches to deal with cross-contamination and transfer 
446 in food products ${ }^{(36-41)}$, and a particularly interesting approach is proposed by Smid et al. ${ }^{(42)}$,

447 taking into account the uncertainty generated in transfer experiments. Here, we preferred to use

448 a binomial process, assuming a mechanistic approach regarding the transfer of cells ${ }^{(38)}$, but the

449 model can be updated in order to consider new evidence about the transfer of different hazards in 450 pork.

451 The model applied to Salmonella has shown that the manipulation parameters and the initial 452 contamination of the carcass surfaces and the lymph nodes are the most important for the surface 453 contamination after inspection. Although some studies have reported bacterial quantification on 454 carcass surfaces ${ }^{(43,44)}$, these studies are scarce and they do not always account for quantification 455 immediately before the inspection point. To our knowledge, no data are available on Salmonella 456 concentrations in the lymph nodes of pigs, whereas the model shows that this information is 457 essential to assess the impact of cross-contamination during meat inspection.

458 Although the traditional meat inspection procedures aim to protect human health, our results 459 show that the cutting and handling of the carcasses and organs during inspection may also have 460 the opposite effect. According to Hill et al. ${ }^{(14)}$ modernization of meat inspection towards to 461 visual-only approach does not seem to be a threat to public health. However, these authors also 462 identify a lack of knowledge regarding cross-contamination during the traditional pig carcass 463 inspection and indicate that this information is needed. Furthermore, Ravel et al. ${ }^{(45)}$ discuss that 464 during the traditional inspection system, cross-contamination can occur between the lymph nodes 465 and other parts of the same carcass or even between consecutive carcasses, but the cross466 contamination level has not been described so far. ${ }^{(45)}$

467 The results, also, highlight the importance of bacterial transfer between carcass surface, hands 468 and lymph nodes if a high number of animals carrying Salmonella in lymph nodes are expected. 
469 Furthermore it sheds some light on the potential inadequacy of classic pig carcass inspection and

470 therefore it can be considered as a tool to quantify the effects of cross-contamination and answer

471 questions about the modernization of the classic carcass inspection system for the

472 implementation of risk-based approaches in meat-inspection. ${ }^{(46)}$

\section{5. CONCLUSIONS}

474 In the classic veterinary meat inspection of pig carcasses, the effect of cross-contamination may 475 not be negligible. The model presented in this paper offers a tool to quantify these effects. Our 476 analyses how that, especially when animals that carry high concentrations of Salmonella in 477 lymph nodes are entering the slaughterhouse, bacteria will be spread to many previously 478 uncontaminated carcasses. The model had not been validated, so far, and this step is important to 479 figure out the suitability of this model in describe cross-contamination during classic inspection 480 procedures and support the modernization of inspection of pig carcass.

482 ACKNOWLEDGMENTS

483 This project was founded by Brazilian National Council for Scientific and Technological 484 Development $(\mathrm{CNPq})$ and National Council for the Improvement of Higher Education (CAPES), 485 who supported a one year research stay at DTU in Denmark for the first author. The authors 486 thank Luis Eduardo da Silva for the data provided, Germano Musskopf for allowing us to follow 487 and quantify the inspection procedures in the slaughterhouse under his supervision, Daniel Pain 488 and Gabriela Werlang for their help during the data collection and Maria Cristina Varriale for her 489 help in notations and formulas.

\section{REFERENCES}


491 1. OIE. Control of biological hazards of animal health and public health importance through 492 ante and post-mortem meat inspection. P. in Terrestrial Animal Health Code. 24th ed. 493 Paris: World Organization for Animal Health (OIE), 2015.

494 2. Codex Alimentarius Commission (CAC). Code of Hygienic Pratice for Meat. Rome: $495 \quad$ FAO, CAC/RCP, 2005.

496 3. Edwards DS, Johnston AM, Mead GC. Meat inspection: an overview of present practices 497 andfuture trends. The Veterinary Journal, 1997; 154(2):135-147.

498 4. Von Ostertag R. Handbuch Der Fleischbeschau Für Tierärzte, Ärzte Und Richter. F. Enke 499 (ed). Stuttgard, 1892.

500

5. EFSA. Scientific Opinion on the public health hazards to be covered by inspection of meat 501 ( swine ) 1. The EFSA journal, 2011; 9(10):1-198.

6. FAO. Responding to the "Livestock Revolution" - the case for livestock public policies. The Livestock Policy Briefs, 2005:1-8.

$5047 . \quad$ Robinson TP, Thornton PK, Franceschini G, Kruska RL, Chiozza F, Notenbaert A, Cecchi 505 G, Herrero M, Epprecht M, Fritz S, You L, Conchedda G, See L. Global Livestock $506 \quad$ Production Systems., 2011.

507 8. Davies PR. Intensive Swine Production and Pork Safety. Foodborne pathogens and $508 \quad$ disease, 2010; 8(2):189-201.

509 9. Nissen S, Poulsen IH, Nejsum P, Olsen A, Roepstorff A, Rubaire-Akiiki C, Thamsborg 510 SM. Prevalence of gastrointestinal nematodes in growing pigs in Kabale District in Uganda. Tropical animal health and production, 2011; 43(3):567-72. 
512 10. Davies P., Morrow WE., Deen J, Gamble H., Patton S. Seroprevalence of Toxoplasma

513 gondii and Trichinella spiralis in finishing swine raised in different production systems in

$514 \quad$ North Carolina, USA. Preventive Veterinary Medicine, 1998; 36(1):67-76.

515 11. Kich JD, Coldebella A, Morés N, Nogueira MG, Cardoso M, Fratamico PM, Call JE, 516 Fedorka-Cray P, Luchansky JB. Prevalence, distribution, and molecular characterization 517 of Salmonella recovered from swine finishing herds and a slaughter facility in Santa 518 Catarina, Brazil. International Journal of Food Microbiology, 2011; 151(3):307-313.

519 12. Blaha T, Meemken D, Dickhaus CP, Klein G. Proposals for designing the food chain 520 information for the implementation of the risk-oriented ante- and post-mortem meat 521 522 inspection. Deutsche tierärztliche Wochenschrift, 2007; 114(8):309-316.

13. Commission Regulation (EU) No 219/2014 of 7 March 2014 amending Annex I to Regulation (EC) No 854/2004 of the European Parliament and of the Council as regards the specific requirements for post-mortem inspection of domestic swine. Text with EEA relevance. 2014:99-100.

14. Hill A, Brouwer A, Donaldson N, Lambton S, Buncic S, Griffiths I. A risk and benefit assessment for visual-only meat inspection of indoor and outdoor pigs in the United Kingdom. Food Control, 2013; 30(1):255-264.

15. Nauta M, Van Der Fels-Klerx I, Havelaar A. A poultry-processing model for quantitative microbiological risk assessment. Risk Analysis, 2005; 25(1):85-98.

16. Bessa MC, Costa M da, Cardoso M. Prevalência de Salmonella sp em suínos abatidos em frígoríficos do Rio Grande do Sul. Pesquisa Veterinária Brasileira, 2004; 24(2):80-84. 
lymph nodes, tonsils, mandibular lymph nodes and carcasses of pigs slaughtered for consumption. Journal of veterinary medicine. B, Infectious diseases and veterinary public health, 2005; 52(10):476-481.

18. FAO. Manual on Meat Inspection for Developing Countries. Herenda D, Chambers PG,

Ettriqui A, Seneviratna P, Silva TJP da (eds). Rome: Food and Agriculture Organization of the United Nations and World Health Organization, 1994.

19. Brasil. Portaria $N^{0} 711$, de $1^{\circ}$ de Novembro de 1995. Brazil: Ministerio da Agricultura Pecuária e Abastecimento (MAPA), 1995:98.

20. da Silva LE, Dias V, Ferronatto A, Guerra P, Berno L, Triches N, Kich JD, Corbellini LG, Cardoso M. Longitudinal dissemination of Salmonella enterica clonal groups through the slaughter process of Salmonella-positive pig batches. Journal of food protection, 2012; 75(9):1580-8.

21. Kim S, Bahk G, Ding T, Kim TW, Oh DH. Adherence Rates of Salmonella Typhmurium ans Salmonella spp. in pork Meat Contaminated during Processing. Korean Society of Food Science and Technology, 2008; 40(3):349-353.

22. Hong C-H, Bahk G-J. Comparison of Cross-contamination of Salmonella spp. on Pork Meat and Workers' Hands during Pork Cutting Processing. Korean Journal for Food Science of Animal Resources, 2008; 28(5):562-566.

23. Corbellini LG, Júnior AB, de Freitas Costa E, Duarte ASR, Albuquerque ER, Kich JD, Cardoso M, Nauta M. Effect of slaughterhouse and day of sample on the probability of a pig carcass being Salmonella-positive according to the Enterobacteriaceae count in the largest Brazilian pork production region. International Journal of Food Microbiology, 
557 24. Vieira-Pinto M, Tenreiro R, Martins C. Unveiling contamination sources and

dissemination routes of Salmonella sp. in pigs at a Portuguese slaughterhouse through macrorestriction profiling by pulsed-field gel electrophoresis. International journal of food microbiology, 2006; 110(1):77-84.

25. Gragg SE, Loneragan GH, Nightingale KK, Brichta-Harhay DM, Ruiz H, Elder JR, Garcia LG, Miller MF, Echeverry A, Ramírez Porras RG, Brashears MM. Substantial within-Animal Diversity of Salmonella Isolates from Lymph Nodes, Feces, and Hides of Cattle at Slaughter. Applied and Environmental Microbiology, 2013; 79(15):4744-4750.

26. Broadway P, Carroll J, Brooks J, Donaldson J, Sanchez N, Schmidt T, Brown T, Callaway T. Salmonella prevalence of lymph nodes and synovial fluid of orally inoculated swine. Agriculture, Food and Analytical Bacteriology, 2015; 5(1):6-8.

27. Delhalle L, De Sadeleer L, Bollaerts K, Farnir F, Saegerman C, Korsak N, Dewulf J, De Zutter L, Daube G. Risk factors for Salmonella and hygiene indicators in the 10 largest Belgian pig slaughterhouses. Journal of food protection, 2008; 71(7):1320-1329.

28. Hald T, Wingstrand A, Swanenburg M, von Altrock A, Thorberg BM. The occurrence and epidemiology of Salmonella in European pig slaughterhouses. Epidemiology and infection, 2003; 131(3):1187-1203.

29. Prendergast DM, Duggan SJ, Fanning S, Cormican M, Gonzales-Barron U, Butler F, Duffy G. Prevalence and numbers of Salmonella spp. and Enterobacteriaceae on pork cuts in abattoirs in the Republic of Ireland. Journal of applied microbiology, 2008; 105(4):1209-1219. 
578 30. Jongenburger I, den Besten HMW, Zwietering MH. Statistical aspects of food safety

579 sampling. Annual review of food science and technology, 2015; 6:479-503.

580 31. Swart AN, Evers EG, Simons RLL, Swanenburg M. Modeling of Salmonella

581 Contamination in the Pig Slaughterhouse. Risk Analysis, 2016; 36(3):498-515.

582 32. Snary EL, Swart AN, Simons RRL, Domingues ARC, Vigre H, Evers EG, Hald T, Hill 583 AA. A Quantitative Microbiological Risk Assessment for Salmonella in Pigs for the $584 \quad$ European Union. Risk analysis, 2016; 36(3):437-449.

585 33. Zwietering MH. Quantitative risk assessment: Is more complex always better?. Simple is 586 587 588 589 590

36. Møller C, Nauta M, Christensen BB, Dalgaard P, Hansen TB. Modelling transfer of Salmonella Typhimurium DT104 during simulation of grinding of pork. Journal of Applied Microbiology, 2012; 112(1):90-98. modelling bacterial transfer to foods: a review. Trends in Food Science and Technology, 2008; 19(3):131-144. 
600

601

602

603

604

605

606

607

608

609

610

611

612

613

614

615

616

617

618

619

620

621

38. Carrasco E, Morales-Rueda A, García-Gimeno RM. Cross-contamination and recontamination by Salmonella in foods: A review. Food Research International, 2012; 45(2):545-556.

39. Gill CO, Jones T. Effects of wearing knitted or rubber gloves on the transfer of Escherichia cohi between hands and meat. Journal of Food Protection, 2002; 65(6):10458.

40. Lariviere-Gauthier G, Quessy S, Fournaise S, Letellier A, Fravalo P. Different types of stainless steel used in equipment in meat plants do not affect the initial microbial transfer, including pathogens, from pork skin. Canadian journal of veterinary research $=$ Revue canadienne de recherche veterinaire, 2015; 79(3):255-259.

41. Ivanek R, Gröhn YT, Wiedmann M, Wells MT. Mathematical model of Listeria monocytogenes cross-contamination in a fish processing plant. Journal of food protection, 2004; 67(12):2688-2697.

42. Smid J, de Jonge R, Havelaar AH, Pielaat A. Variability and uncertainty analysis of the cross-contamination ratios of salmonella during pork cutting. Risk analysis: an official publication of the Society for Risk Analysis, 2013; 33(6):1100-1115.

43. Van Damme I, Berkvens D, Vanantwerpen G, Bare J, Houf K, Wauters G, De Zutter L. Contamination of freshly slaughtered pig carcasses with enteropathogenic Yersinia spp.: Distribution, quantification and identification of risk factors. International journal of food microbiology, 2015; 204:33-40.

44. Warriner K, Aldsworth TG, Kaur S, Dodd CER. Cross-contamination of carcasses and equipment during pork processing. Journal of Applied Microbiology, 2002; 93(1):169_ 
45. Ravel A, Sidibé B, Moreau P, Bisaillon J-R. Risk-Benefit Assessment of Hog Mandibular Lymph Node Incision at Slaughter in Canada. Journal of Food Research; Vol 4, No 6 (2015), 2015.

46. FAO. Risk-Based Food Inspection Manual. Rome: Food and agriculture organization of 627 the united antions, 2008.

47. Nauta M, Barfod K, Hald T, Sørensen AH, Emborg H-D, Aabo S. Prediction of Salmonella carcass contamination by a comparative quantitative analysis of E. coli and Salmonella during pig slaughter. International journal of food microbiology, 2013; 166(2):231-7.

632

634 Appendix A. Values used in the empirical distribution that is applied to sample the number of 635 interactions between carcass/organ with hands, knife and hook using the index $A e=(H, K$, G). Probabilities in columns sum up to 1

\begin{tabular}{lccc}
\hline Counts & $J_{i, A c, H}$ & $J_{i, A c, G}$ & $J_{i, A c, K}$ \\
\hline 0 & 0.009 & 0 & 0 \\
1 & 0.009 & 0.017 & 0.008 \\
2 & 0.018 & & 0.051
\end{tabular}




\section{Appendix B}

639 It is assumed that the concentrations on the carcass surfaces before inspection $\left[C_{i(S-1)}\right]$ can be 640 described by a zero inflated lognormal distribution with prevalence $p$ and thus a probability of an

641 uncontaminated carcasses 1-p. Let $u=\log _{10}(x)$ and the probability density function $f(u)$ for 642 concentration $\left[C_{i(S-1)}\right]$, can be defined by:

$643 \quad f(u)=\left\{\begin{array}{lr}p * \frac{1}{\sigma \sqrt{2 \pi}} e^{-\frac{1}{2}\left(\frac{u-\mu}{\sigma}\right)^{2}} & u>L O Q \\ p * \int_{L O D}^{L O Q} \frac{1}{\sigma \sqrt{2 \pi}} e^{-\frac{1}{2}\left(\frac{u-\mu}{\sigma}\right)^{2} d u} & L O D<u<L O Q \\ (1-p)+\left(p * \int_{0}^{L O D} \frac{1}{\sigma \sqrt{2 \pi}} e^{-\frac{1}{2}\left(\frac{u-\mu}{\sigma}\right)^{2}} d u\right) & u<L O D\end{array}\right.$

644 Where $L O Q$ and $L O D$ are limits of quantification and detection of Salmonella, respectively.

645 Applying this probability density function to each sample $x_{i}$ for carcass surfaces $i$ in the study

646 from da Silva et al. ${ }^{(20)}$, the parameters $(\mu, \sigma$ and $p)$ were assessed by the Maximum Log

647 likelihood estimation using the Solver function in Excel, i.e. maximizing

$648 \quad \sum_{i=1}^{n} \log f\left(x_{i} ; \mu, \sigma, p\right)$ 
649 Where, $i$ is the carcass number and $n$ is the last carcass sampled.

650

651 Appendix C

652 Consider a system with two compartments $E$ and $C$ in which a sequence of events (in this case

653 the manipulations: cuts, touches or hookings) is defined by the index $J$, with $J \in \mathrm{N}$ indicating the

654 number of manipulations. Also consider no loss and no increase of units, only transfer is

655 modeled with a given initial condition:

$656 E_{0}=100 \mathrm{CFU}$

657 The transfer probability from the compartment $E$ to the $C$ is called $q$, and it is assumed to be

658 constant through the sequential steps $J$.

659 So, the amount on the $E$ compartment after $J$ steps is the amount before the step $J$ minus a

660 fraction $q$ :

$661 \quad E_{J}=E_{J-1}-\left(E_{J-1} * q\right)$

662 so

$663 E_{J}=E_{J-1} *(1-q)$

664 This applies to $J$ subsequent steps, so.

665

$$
\left\{\begin{array}{l}
E_{1}=E_{0} *(1-q) \\
E_{2}=E_{0} *(1-q) *(1-q) \\
E_{3}=E_{0} *(1-q) *(1-q) *(1-q) \ldots \\
\boldsymbol{E}_{\boldsymbol{J}}=\boldsymbol{E}_{\mathbf{0}} *(\mathbf{1}-\boldsymbol{q})^{J}
\end{array}\right.
$$

666 In the stochastic model this is interpreted as a Binomial process, with $\mathrm{N}=E_{0}$ and $\mathrm{p}=(1-q)^{J}$. For 667 example in equation (1), considering the term $\left(1-b_{C, A e}\right)^{J_{i, C, A e}}$. It was implemented by sampling 
668 values from a Binomial distribution as: $\sim \operatorname{Binomial}\left(C_{i,(S-1), A e} ;\left(1-b_{C, A e}\right)^{J_{i, C, A e}}\right)$ describing the

669 number of cells not transferred to from carcass to environment after $J$ interactions.

670 Using the previous equation (Appendix C) we can derive the amount of Salmonella in

671 compartment $C$. Considering the fact that only transfer between two compartments is possible

672 (no die off or growth), the amount in $C$ is the difference between the $E_{0}$ and the $E_{J}$. Applying it

673 in the previous equations:

$674 C_{J}=E_{0}-\left(E_{0} *(1-q)^{J}\right)$

675 so

$676 C_{J}=E_{0} *\left(1-(1-q)^{J}\right)$

677

678

679

680 Appendix D. Parameters, baseline, minimum and maximum values used during the univariate

681 sensitivity analyses. See tables I and II for an explanation of the parameter symbols and indices.

\begin{tabular}{lcccc}
\hline Parameters & Baseline $(\mathrm{y})$ & Maximum $\left(\mathrm{y}^{+}\right)$ & Minimum $\left(\mathrm{y}^{-}\right)$ & Unit \\
\hline$a_{K, C}$ & 0.17 & 100 & 0 & $\%$ \\
$a_{K, O}$ & 0.17 & 100 & 0 & $\%$ \\
$b_{C, K}$ & 0.17 & 100 & 0 & $\%$ \\
$b_{O, K}$ & 0.17 & 100 & 0 & $\%$ \\
$a_{H, C}$ & 0.21 & 100 & 0 & $\%$ \\
\hline
\end{tabular}




\begin{tabular}{|c|c|c|c|c|}
\hline$a_{H, O}$ & 0.21 & 100 & 0 & $\%$ \\
\hline$b_{C, H}$ & 3.1 & 100 & 0 & $\%$ \\
\hline$b_{O, H}$ & 3.1 & 100 & 0 & $\%$ \\
\hline$a_{G, C}$ & 0.17 & 100 & 0 & $\%$ \\
\hline$a_{G, O}$ & 0.17 & 100 & 0 & $\%$ \\
\hline$b_{C, G}$ & 0.17 & 100 & 0 & $\%$ \\
\hline$b_{O, G}$ & 0.17 & 100 & 0 & $\%$ \\
\hline$d_{C}$ & 0 & 100 & 0 & $\%$ \\
\hline$d_{o}$ & 0 & 100 & 0 & $\%$ \\
\hline $\mathrm{ka}$ & 10 & 15 & 5 & $\mathrm{~cm}^{2}$ \\
\hline ha & 150 & 200 & 100 & $\mathrm{~cm}^{2}$ \\
\hline $\mathrm{ga}$ & 1 & 3 & 0.5 & $\mathrm{~cm}^{2}$ \\
\hline$\mu \log _{10}\left[C_{i(s-1)}\right]$ & -5.2 & 2 & -15 & $\log _{10} \mathrm{CFU} / \mathrm{cm}^{2}$ \\
\hline$\sigma \log _{10}\left[C_{i(s-1)}\right]$ & 2.2 & 4 & 0 & $\log _{10} \mathrm{CFU} / \mathrm{cm}^{2}$ \\
\hline $\operatorname{PrevO}_{i(s-1)}$ & 14.1 & 100 & 0 & $\%$ \\
\hline $\operatorname{Prev}_{i(s-1)}$ & 100 & 100 & 0 & $\%$ \\
\hline$\left[O_{i(s-1)}\right] \mathrm{Min}$ & 0.01 & 0.1 & 0.0001 & $\mathrm{CFU} / \mathrm{cm}^{2}$ \\
\hline$\left[O_{i(s-1)}\right] \mathrm{MP}$ & 1 & 100 & 0.01 & $\mathrm{CFU} / \mathrm{cm}^{2}$ \\
\hline$\left[O_{i(s-1)}\right] \mathrm{Max}$ & 100 & 1000 & 10 & $\mathrm{CFU} / \mathrm{cm}^{2}$ \\
\hline
\end{tabular}

$682 \mu=$ mean; $\sigma=$ standard deviation; $\mathrm{Min}=$ minimum; $\mathrm{MP}=$ most likely; $\mathrm{Max}=$ maximum values in 683 triangular distribution 
685 Appendix E. Parameter values for scenarios used in multivariate sensitivity analyses. The scenarios: no transfer and no contamination were omitted

\begin{tabular}{|c|c|c|c|c|c|c|c|}
\hline \multirow[b]{4}{*}{ Parameters } & & \multicolumn{6}{|c|}{ Scenarios } \\
\hline & \multirow[b]{3}{*}{ Baseline } & & & \multirow{3}{*}{$\begin{array}{c}\text { Hand influence } \\
\text { high } \\
\log _{10}\left[C_{i(s-1)}\right]\end{array}$} & \multicolumn{2}{|l|}{ Hand influence } & \multirow{3}{*}{$\begin{array}{l}\text { Hand Influence high } \\
\operatorname{PrevO}_{i(s-1)}\end{array}$} \\
\hline & & & & & high & Hand Influence & \\
\hline & & Only carcass (S-1) & Only LN (S-1) & & $\sigma \log _{10}\left[C_{i(s-1)}\right]$ & $\operatorname{high}\left[O_{i(S-1)}\right]$ & \\
\hline $\operatorname{Prev}_{i(S-1)}$ & $100 \%$ & $100 \%$ & $0 \%$ & $100 \%$ & $100 \%$ & $100 \%$ & $100 \%$ \\
\hline $\operatorname{PrevO}_{i(s-1)}$ & $14.4 \%$ & $0 \%$ & $14.1 \%$ & $14.1 \%$ & $14.1 \%$ & $14.1 \%$ & $100 \%$ \\
\hline$a_{H, C}$ & $0.21 \%$ & $0.21 \%$ & $0.21 \%$ & $10 \%$ & $10 \%$ & $10 \%$ & $10 \%$ \\
\hline$b_{C, H}$ & $3.1 \%$ & $3.1 \%$ & $3.1 \%$ & $10 \%$ & $10 \%$ & $10 \%$ & $10 \%$ \\
\hline$\mu \log _{10}\left[C_{i(S-1)}\right]$ & -5.4 & -5.4 & 0 & -3 & -5.4 & -5.4 & -5.4 \\
\hline$\sigma \log _{10}\left[C_{i(S-1)}\right]$ & 2.2 & 2.2 & 0 & 2.2 & 3.3 & 2.2 & 2.2 \\
\hline$\left[O_{i(S-1)}\right] \mathrm{Min}$ & 0.01 & 0 & 0.01 & 0.01 & 0.01 & 0.1 & 0.01 \\
\hline$\left[O_{i(S-1)}\right] \mathrm{MP}$ & 1 & 0 & 1 & 1 & 1 & 10 & 1 \\
\hline$\left[O_{i(s-1)}\right] \operatorname{Max}$ & 100 & 0 & 100 & 100 & 100 & 1000 & 100 \\
\hline
\end{tabular}

$\mu=$ mean; $\sigma=$ standard deviation; $\mathrm{LN}=$ Lymph nodes; Min=minimum; $\mathrm{MP}=$ most probable; $\mathrm{Max}=$

maximum values in triangular distribution

\section{Appendix F}

690 Adopting Jongenburger's approach ${ }^{(30)}$ the observed prevalence will be a product of the factor $l$

691 and the modeled prevalence. The value of $l$ can be considered as a probability that at least one

692 sample unit (CFU) is drawn from an inspected area: $l=P(\mathrm{x} \geq 0)$. This probability follows as a

693 hypergeometric distribution. Consider four swabs taken with a sponge in fixed and mutually

694 exclusive areas of $100 \mathrm{~cm}^{2}$ on carcass surface $(n=4)$. Next, consider the whole carcass area as

$69514000 \mathrm{~cm}^{2(47)}$ represented as a rectangle composed by $N=14000 / 100=140$ different $N$ areas that

696 can potentially be sampled.

697 According to the model the total area inspected per carcass during meat inspection is on average

$698700 \mathrm{~cm}^{2}$ (data not shown), and the number of possible inspected areas sampled is $K=700 / 100=7$

699 different areas. The probability that at least one sample is drawn from the inspected areas is (1- 
$700 \mathrm{P}(x=0))$ has hypergeometric distribution according:

$701 \quad P(x=0)=\frac{\left(\begin{array}{l}K \\ x\end{array}\right)\left(\begin{array}{l}N-K \\ n-x\end{array}\right)}{\left(\begin{array}{l}N \\ n\end{array}\right)}=\frac{\left(\begin{array}{c}7 \\ 0\end{array}\right)\left(\begin{array}{c}140-7 \\ 4-0\end{array}\right)}{\left(\begin{array}{c}140 \\ 4\end{array}\right)} \approx 81 \%$

702 So, $1-\mathrm{P}(x=0)=19 \%$ is the $l$ factor. 